First Peoples Child \& Family Review

An Interdisciplinary Journal Honouring the Voices, Perspectives, and Knowledges of

First Peoples through Research, Critical Analyses, Stories, Standpoints and Media

Reviews

\title{
Inuit Youth Transitioning out of Residential Care: Obstacles to Re-integration and Challenges to Wellness
}

\author{
Sarah L. Fraser, Mélanie Vachon, Maria J. Arauz, Cécile Rousseau and \\ Laurence J. Kirmayer
}

Volume 7, Number 1, 2012

URI: https://id.erudit.org/iderudit/1068865ar

DOI: https://doi.org/10.7202/1068865ar

See table of contents

Publisher(s)

First Nations Child and Family Caring Society of Canada

\section{ISSN}

1708-489X (print)

2293-6610 (digital)

Explore this journal

\section{Cite this article}

Fraser, S., Vachon, M., Arauz, M., Rousseau, C. \& Kirmayer, L. (2012). Inuit Youth Transitioning out of Residential Care: Obstacles to Re-integration and Challenges to Wellness. First Peoples Child \& Family Review, 7(1), 52-75. https://doi.org/10.7202/1068865ar

\section{Article abstract}

For youth under child welfare, transitioning out of residential care and reintegrating into their community can be a difficult process. This may be especially true for Inuit youth who, because they are away from their communities, cannot develop networks and relationships that would provide a secure place for their development as an adult and as a community member. The objectives of this study were to document how transition out of care is addressed in a residence specialized for Inuit youth under government care, and to explore, from the perspective of residential managers and staff, what factors facilitate or create obstacles to successful transition. Interviews were conducted to discuss the transition of 11 youth from residential placement back into communities. The criteria used by managers and staff to describe transitions mostly focused on the behaviours of the youth and the ability to create and implement a plan. Are current theme was the importance of continuity and connections with family, staff, and culture. Various measures were put into place around the current system of care in order to facilitate continuity and connections to respond to the cultural and personal needs of youth. To enhance the "cultural competence" of care, we suggest that: (i) criteria for successful and unsuccessful transitions be determined with youth, families, and communities; (ii) that Inuit representation in care be increased; and (iii) that measures be taken outside the current system of care to encourage shifts in power distribution.
Copyright @ Sarah L. Fraser, Mélanie Vachon, Maria J. Arauz, Cécile Rousseau, Laurence J. Kirmayer, 2012
This document is protected by copyright law. Use of the services of Érudit (including reproduction) is subject to its terms and conditions, which can be viewed online.

https://apropos.erudit.org/en/users/policy-on-use/ 


\title{
First Peoples Child \& Family Review
}

An Interdisciplinary Journal Honoring the Voices, Perspectives and Knowledges of First Peoples through Research, Critical Analyses, Stories, Standpoints and Media Reviews

\section{Inuit Youth Transitioning out of Residential Care: Obstacles to Re-integration and Challenges to Wellness}

\author{
Sarah L. Frasera, Mélanie Vachonª, Maria J. Arauz ${ }^{b}$, Cécile Rousseau $^{c}$, and \\ Laurence J. Kirmayer ${ }^{\mathrm{c}}$, \\ a Université du Québec à Montréal, Department of Psychologie, QC, Canada \\ ${ }^{\mathrm{b}}$ Université de Montréal, Department of Social and Preventative Medecine, QC, Canada \\ ${ }^{b}$ McGill University, Division of Transcultural Psychiatry
}

\begin{abstract}
For youth under child welfare, transitioning out of residential care and reintegrating into their community can be a difficult process. This may be especially true for Inuit youth who, because they are away from their communities, cannot develop networks and relationships that would provide a secure place for their development as an adult and as a community member. The objectives of this study were to document how transition out of care is addressed in a residence specialized for Inuit youth under government care, and to explore, from the perspective of residential managers and staff, what factors facilitate or create obstacles to successful transition. Interviews were conducted to discuss the transition of 11 youth from residential placement back into communities. The criteria used by managers and staff to describe transitions mostly focused on the behaviours of the youth and the ability to create and implement a plan. A recurrent theme was the importance of continuity and connections with family, staff, and culture. Various measures were put into place around the current system of care in order to facilitate continuity and connections to respond to the cultural and personal needs of youth. To enhance the "cultural competence" of care, we suggest that: (i) criteria for successful and unsuccessful transitions be determined with youth, families, and communities; (ii) that Inuit representation in care be increased; and (iii) that measures be taken outside the current system of care to encourage shifts in power distribution.
\end{abstract}

\section{Introduction}

Aboriginal children are highly over-represented in the child welfare systems of Canada (Blackstock, Trocmé, \& Bennett, 2004; Galley, 2010; Lavergne, Dufour, Trocmé \& Larrivée, 2008; Office of the Auditor General, 2011; Trocmé, Knoke, \& Blackstock, 2004). It is estimated that slightly less than a quarter of youth signalled to child welfare services (Blackstock, Trocmé, \& Bennett, 2004; Lavergne, et al., 2008) and approximately 30 to 40 per cent of children placed in outof-home care are of Aboriginal descent (Farris-Manning \& Zandstra, 2003). In recent years, child welfare systems have been compared to the Indian Residential School system, with three times more Aboriginal children under governmental care today than during the most active period

Corresponding author:

Sarah Fraser, CSSS de la Montagne (Parc Extension), 7085 rue Hutchison, Local 204.2; Tél: (514)358-7514; sarah.fraser.1@ulaval.ca of the residential schools (Blackstock \& Trocmé, 2005). Aboriginal children are twice as likely to be placed in out-of-home care, as compared to nonaboriginal children (Trocmé, Knoke, \& Blackstock, 2004). The limited data on Inuit children suggest similar trends in overrepresentation within the 
system of care (Commission des droits de la personne et de la jeunesse, 2007; MacLaurin et al., 2005; Rae, 2011).

Despite this over-representation, to date there have been no studies of the experience of Inuit children in care or on the complex process of transitioning from care back to their communities. The present study was designed to explore how managerial and educational staff of an outof-community residence for Inuit youth (aged 12-18) perceived the obstacles to reintegration for youth transitioning back to their communities. A secondary aim was to explore how these same managers and staff prepared youth for transition as a function of their perceptions and understandings of obstacles to reintegration and challenges to wellness.

\section{Background}

As Lafrance and Bastien (2007, p. 98) note, "[m]any are concerned that the child welfare experience may inadvertently parallel the colonial experience of residential schools and may have similar long-term negative ramifications for Aboriginal communities." Most often, the placement of Aboriginal children in care, including First Nations, Inuit, and Métis, is the result of a prolonged experience of economic poverty, parental neglect, lack of social support, and cultural oppression (Blackstock \& Trocmé, 2005; Cunneen \& Libesman, 2000; Galley, 2010; Trocmé, Knoke, \& Blackstock, 2004).

Opinions on the impact of residential care on youth and their families in child welfare are divided. Some suggest that residential programs should not be viewed as last resort care but rather as preferential care for high-risk youth in need of high levels of structure (Anglin, 2004; Hillan, 2005; Lieberman, 2004; Lyons, Woltman, Martinovich, \& Hancock, 2009). Some studies have observed various positive short-term gains among youth in residential programs, including reduced symptomology (Larzelere, et al., 2001; Lyons et al., 2009; Slot, Jagers, \& Dangel, 1992), reduced delinquency (Kirgin, Braukmann, Atwater, \& Wolf, 1982), and better general functioning (Blackman, Eustace \& Chaudhury, 1991). However, some studies have found that these gains are short-lived (Bates, English, \& Kouidon-Giles, 1997; Frensch \& Cameron, 2002; Kirgin, Braukmann, Atwater, \& Wolf, 1982; Slot, Jagers, \& Dangel, 1992).

These studies have been conducted in the general population and use behavioural criteria to assess the impacts of care. Given the specific cultural, social, and economic reality of Aboriginal people in Canada, - which includes a long history of oppression with the removal of Aboriginal youth from families and communities - it is unclear how generalizable these results are to Aboriginal children generally, and Inuit in particular. Few, if any, impact studies have been performed among Aboriginal children in care. However, Lafrance and Bastien (2007) write: "we are learning from the stories gathered in our work that the outcomes of current child welfare interventions for many Aboriginal children have been abysmal, and in some respects, worse than those of the residential school system." What has been clearly established is the lack of culturally adapted services for Aboriginal youth in Canada (Office of the Auditor General, 2011) and for Inuit children specifically (Rae, 2011). As a result of this recognition, a priority recommendation was made by the Office of the Auditor General to determine the needs of youth and elaborate definitions of culturally appropriate care (Office of the Auditor General, 2011).

As noted in the Aboriginal Justice Commission, "The interpretation of child welfare legislation is an area where cross-cultural misunderstanding frequently occurs. Terms such as 'adequate care,' 'proper supervision' and 'unfit circumstances,' not to speak of 'in the best interests' and 'in 


\section{Inuit youth transitioning out of residential care}

need of protection,' are vague and value-laden." The intercultural context is challenging, at best. An essential step in the process of providing culturally competent care is that practitioners and institutions familiarize themselves with their own cultures and practices as well as with the power structures within their systems of care (Cross, Bazron, Dennis, \& Isaacs, 1989; Kalyanpur, 1998; Negi, Bender, Furman, Fowler, \& Prickett, 2010; Pierce \& Pierce, 1996). Culture is understood here as the lens, acquired in a developmental process of socialization, through which we view the world and our relationships. This lens influences how we think, feel, and act, and objectively and symbolically ties us to a collectivity (Bruner, 1993; Camilleri, 1989; Rocher, 1969). Cultural competence is defined as "the ability of systems to provide care to patients with divers values, beliefs and behaviors, including tailoring delivery to meet patients' social, cultural, and linguistic needs" (Betancourt et al., 2003).

Of course, how these broad ideas about culture are implemented in specific institutional practices remains unclear. A critical analysis of the institutional perceptions and actions in child welfare could allow Inuit people, who often have little power within the structures they must navigate, to become aware of the cultures that guide the development of programs and practices.

Transitioning out of care and reintegrating with the community can be a very difficult process, compromising any potential gains made in care. Studies among Euro-American and Canadian youth in care suggest that the most significant factors associated with maintained gains (i.e., higher self-esteem, reduction in severity of psychological symptoms, ability to adapt to the community environment) post discharge are family involvement (Hair, 2005; Stage, 1999), stability of postplacement, and after-care services (Burns, Hoagwood, \& Mrazek, 1999; Frensch \& Cameron, 2002). As noted, these findings cannot be automatically generalized to Inuit who face specific social, cultural, historical, and political realities. To our knowledge, no published studies to date have looked at the factors that facilitate transition among Inuit or other Aboriginal youth in care. Given that many features of Inuit youth and communities are distinctive, there is an urgent need for research in this area.

The present study examined the issues of cultural competence in transitioning out of residential care. The objectives were to unpack the views of managers and staff members in a new residential program related to the experience of Inuit youth transitioning out of residence, and to explore how these perceptions influenced the development of programs as related to transitioning home. This topic was a central concern to our Inuit research partners.

\section{Method}

The present study grew out of a regional initiative. In response to the large number of youth in care and the lack of human resources and infrastructure in a specific region of Canada, an out-ofcommunity residential service was recently developed specifically for Inuit youth. The mandate of the residential staff was to "stabilize" youth in crisis. To do so, they were requested to develop and implement a "clinically" and "culturally" appropriate program. Neither of these terms was clearly described by the institution. The program was developed and run by non-Aboriginal professionals, with consultation from an Inuit individual hired as an educator by the residence as well as an Inuit Elder. Non-Aboriginal individuals made all decisions regarding preparation for transition as a function of their understanding of the reality of the youth they were working with.

The residence was in an urban centre, far from the youths' home communities. The health and social services of the communities serviced by the residence partnered with an urban-based 
First Peoples Child \& Family Review, Volume 7, Number 1, 2012

centre specialized in rehabilitative program development for youth and young adults presenting psycho-social, emotional, and/or behavioural difficulties. This centre contacted a small group of clinician-researchers specialized in cultural psychiatry/psychology, and more specifically in Aboriginal wellbeing, for assistance in program development and evaluation. The centre hired the first author of this paper (SF) as a research consultant three hours a week to participate in program development meetings, offer suggestions as to methods for quality assurance evaluation, and supervise the quality assurance process. SF was able to dedicate additional time to this project as a post-doctoral fellow under the supervision of senior authors (CR and LJK). The primary author developed methods of investigation with consultation from two Inuit individuals. All methods were then discussed with the three partners involved: the residential managers, the urban-based centre contracted for program development, and the regional health and social service institution. The administrators made final decisions as to what methods would be used.

\section{Description of the program}

The residence was developed in 2010 in order to fill a gap in specialized welfare services for Inuit adolescents 12-18 years of age. As a last resort placement, the residence mostly received youth with high-risk behaviours, alcohol and substance abuse, suicidal attempts, and/or violent behaviours. These behaviours evolved in various contexts of personal, family, and transgenerational trauma in contexts of structural violence, poverty, and inadequate housing (Rae, 2011).

Until 2010, provincial youth protection services in city centres were being used for youth for whom foster homes and in-community placement were not possible, generally due to the highrisk behaviours of youth and lack of placements in communities. They were therefore integrated into programs developed for the general population. A total of eight girls and eight boys could be received at a time within these facilities, and they stayed from three to twelve months before moving on to other services or returning home. Over the initial 14-month period of the program, a total of 23 youth stayed at the residence.

Over the initial 14-month period of the program, during which the internal quality assessment took place, almost all staff hired were non-Aboriginal; however, there were generally always two Inuit educators on staff. Due to their specific experiences and knowledge surrounding the reality, culture, and language of the youth, they were often asked to give advice to non-Aboriginal staff, to the program development committee, and to the researchers. As well, they led certain traditional activities, met youth individually when required, and translated or interpreted for youth and staff members when necessary.

\section{Conceptual and methodological approach}

An interactionist perspective was adopted as a conceptual framework. The interactionist perspective is based on the premise that human beings are best understood in an interactive relation to their environment (Blumer, 1969; Prus, 1996). This paradigm views social reality as constructed through personal experiences, culture, and interpersonal interactions. Interviews and observations therefore focused on the managers' and staff's perceptions, relationships, and experiences. The interactionist perspective has been widely used in intercultural contexts (Vachon, 2011) as well as in contexts of social marginalization (Demazière, 2011; Vachon, 2011). 


\section{Inuit youth transitioning out of residential care}

\section{Data Collection}

Interviews. To explore transition out of care, the main sources of data were semi-structured and unstructured interviews with six staff members of the residence, including: (a) two managers, one for the boys' unit and one for the girls' unit; (b) the consultant from the regional health administration in charge of developing the residence; (c) an Inuit staff member; and (d) two therapists. Interviews were approximately 45 minutes in duration and involved a careful exploration of the context and process of transition for each case. They were audio-recorded, transcribed, and analyzed using NVivo (2010). Interviews were conducted with youth on various topics, but they were not interviewed concerning their transition out of care because the scheduling of this was unknown at the time of the interview and follow-up after return to the community could not be arranged for logistical reasons.

Individual logs. Logs were recorded by staff members for each youth at every shift of the day (three times a day) for clinical purposes. Staff recorded the youth's general mood during the shift, special incidents, relationships with peers and staff, contact with parents, and any clinical information pertinent to follow-up.

Observation. Participant observation was used to gather additional information on the transition process of youth. Observation also allowed for better understanding of the social meanings, rules, habits, functioning, and rituals at the residence. This involved many hours of participation in regular activities on residence floors with youth and staff. The main researcher and two research assistants took part in routine activities with the youth (i.e., sewing, girl-talk group, activity centre, smoking breaks) as well as team meetings. Detailed records of observations, decisions, and reflections regarding youth's experience of placement, clinical practices, and organization of care were kept throughout the evaluation process in the form of reflection diaries and videorecorded interviews among research assistants. The main researcher also took part in weekly program development meetings over a four-month period.

\section{Ethical Considerations}

Data were collected as part of a quality assurance process mandated by the Regional Health and Social Service institution in agreement with the Ministry of Health and Social Services at the time that funds were made available for the development of the residence. Accordingly, the hospital IRB, the institutions, and the communities agreed that no formal consent from participants was needed.

The first author conducted data analysis. The data was kept in the possession of the lead researchers for logistical reasons. However, they remained under the ownership and control of the health and social service institution of the communities. An Inuit health board governs this institution.

Approval to further analyze and publish the results was obtained from the health board as well as the Institutional Review Board of the research hospital to which the primary researcher was affiliated as a postdoctoral fellow. In preparing this report, references to clients or other clinical material has been altered to protect participant confidentiality.

Prior to the dissemination of any results, the lead researchers requested permission from the health and social service institution. All material was then presented to Inuit representatives of the major organizations and institutions of the region. 
First Peoples Child \& Family Review, Volume 7, Number 1, 2012

\section{Data Analysis}

We collated data from interviews, reflections from observations, and relevant material from the individual logs. Using NVivo software, qualitative analyses were conducted by a research assistant and two researchers. Data coding followed thematic analysis (Braun \& Clarke, 2006). In the initial phase of this method, interviews, reflective notes, observation notes, and logs were transcribed, read by the research assistants, and re-read by one of the researchers. The lead authors and the research assistants highlighted thoughts and extracts, allowing the emergence of new insights and interpretations. Second, the two lead authors generated initial codes by organizing the material according to the research objectives and coding data that appeared to offer elements relevant to understanding these questions. At this step, multiple in-depth discussions took place among team members. The third phase involved grouping specific codes under more general themes to document facilitators and obstacles to post-treatment transition. During the fourth step, themes and codes were verified and categorized as a function of emerging themes as discussed in phase three. Fifth, we defined all categories (both codes and themes), and linked emerging themes with significant extracts. The sixth step consisted of relating emerging themes with the literature on the subject. Throughout the process of coding and analysis, methodological reflections and decisions were shared and discussed among research assistants and the first two co-authors (SF \& MV) to improve the consistency of interpretations and findings (Malterud, 2001).

\section{Results}

\section{Criteria used to discuss transition}

No a priori criteria were offered to managers and staff members to discuss transitions. Few explicit criteria were used in the interviews. Transition was generally discussed in broad terms, with little detail about what constituted success or failure. In general, managers appeared to base their recommendations of when transition should take place on their assessment of the youth's feelings about transition, the youth's behaviours, the belief that the youth is capable of maintaining the behaviours over time and in a different context, the availability of a place to stay, the family's readiness to offer a safe and healthy environment for the youth and a general consensus between social workers, the youth, the residential staff and family members that youth was "ready."

\footnotetext{
"He [name] was supposed to have another three months with us, but he had done so well that we felt that it was more of a punishment to make him stay, rather than send him back [to the community] and try and fix things for him in the family."

- Manager interview

"So basically it is based on her [youth's] behaviour in the unit, for the most part, which has been acceptable. If that's the criteria you want to use, then yeah, she should go [home]. And if her parents are ready to have her, then she should go. That was basically in a very short period of time."

- Manager interview
}

On various occasions it was mentioned that, despite progress in a youth's behaviour in residence, managers had concerns about the youth's ability to maintain such behaviours in a different context. 


\section{Inuit youth transitioning out of residential care}

"Based on the progress and the behaviour here [in residence], that would indicate that it's time for her to go back [to her community]. And we were saying, OK yeah, but it's been a short period of time and it does not mean that she'll be able to transfer to the community. And so we said, OK let's give her the opportunity to try.

- Manager interview

"I think one of the problems when you work in rehabilitation is that you have to be very careful because the moment somebody starts to make progress then it's OK; it's time for them to go. But often times when they start to make progress, it's the time that you should hold on to more, to secure, and to be sure. 'Cause oftentimes: Ah! Progress! We move along! And it's too early and they fail."

- Manager interview

Managers therefore felt that behaviours and the ability to change within a specific context of care were not sufficient to ensure a smooth reintegration into families and communities. Transitions were viewed positively when the positive behaviours observed in residence were maintained at least partially following their return to the communities. Considering the difficult family and community contexts that youth often returned to, and reflecting their professional training and background, managers and staff adopted a harm reduction philosophy when assessing the "success" of transition. Being able to somewhat resist peer pressure to engage in harmful behaviours, and remaining "functional" by going to school, or maintaining a job despite occasionally returning to harmful behaviours, were viewed as positive adaptations to the community.

Interviewer: "And good [i.e., ready for transition] for you would be that. . ?"

Interviewee: "Well good is that one of the things we know, theoretically and practically, when it comes to substance abuse and severe addictions, to get people to break that habit and stop is very difficult. So what we focus on is harm reduction. So if you're gonna use and you're sure that you're able to use it in a way where you're not putting your health at risk, where it doesn't interfere with your ability to work and hold a job, where it's not to an extent of interfering with your parental relationships, those kinds of things. So I mean in that sense. So if she is, it has reduced to a point in this stage, where it's not being disrupted, as we would think, so she is still in line."

- Manager interview

Interviewee: "Ah, what does she do when she's in difficulty? Ah, she can self-mutilate; selfharm. Umm, she also draws, self-isolates. What's important is she has at least concretely one or two people that she can talk to when she's feeling that way."

Interviewer: "And does she contact them?"

Interviewee: "She does."

- Manager interview

"I know her primary worker continues to speak to her grandmother and mother and they say things are going well; they're pleased with her behaviour. But all of this is relative. As I say, she was in jail for fighting and drinking. And so when they say that they're pleased with her behaviour it's relative. I mean, it's only half [inaudible] since she's been back, this was nothing like it was before. It was something that happened frequently, so yeah...."

- Manager interview 


\section{First Peoples Child \& Family Review, Volume 7, Number 1, 2012}

Finally, when managers and staff had time to establish and implement a plan for transition, this in itself was viewed as a success. Plans, which will be discussed in further detail later, mostly included creating job opportunities, and linking the youth with a specialized service or a resource person. On the other hand, when a plan was implemented or if the youth had to be placed under youth protection again or incarcerated, the transition was viewed negatively.

Interviewee: "Yep. Shed already tried to go [to the community] before. She had tried to leave to go to substance abuse, a treatment facility, and didn't work so was back [a few days] later. Also, before coming to us, she had been in [urban-based youth protection for general population], she had been in the [group home] and she's gone home from there and it hasn't worked and she'd come back."

Interviewer: "So you had the concern that this time it would actually work out?"

Interviewee: "No, I'm saying it was quite different. I'm saying this time we all felt more confident; that it did work out this time. ..."

- Manager interview

"Now that's the one you're going to see where the problems are. ... How much work we had done here and then what he finished in.... He's now in jail."

- Manager interview

Interviewee: "I mean, she's managing it. I mean, you know, she has her moments, but she's been able to stay there. Good for her."

Interviewer: "In what sense do you mean managing right now? "

Interviewee: "I mean she's in [the community]. She's managing to stay there. She's managing to stay in school, even though there are days that she misses, those kinds of things. She often calls back and tells the girls how much she misses here and she wants to come back. But she still plans to stay."

- Manager interview

Youths' desire and ability to remain within the community over time were implicit criteria to what was perceived as a positive reintegration. Transition was rarely viewed frankly as a "success" or "failure" but rather as a complex process in which youth oscillated.

\section{Elements that facilitate a positive transition}

According to the perspective of staff, the main factors that seemed to facilitate transition were various forms of connections to others, to the community, and to culture, as well as continuity of relationships with family during their residential stay and to residence staff following their transition back to their community.

Contact with family and community members throughout youths' stay was perceived as a powerful motivator for youth, encouraging engagement in the program. For example, they reported that youth who had better family and community connections would express their desire to stop using drugs and alcohol, would respect the residence rules in order to please their family and increase the likelihood of returning home quickly. When managers and staff had the impression that family members were actively involved in the care and transition phase, they 


\section{Inuit youth transitioning out of residential care}

felt that this period was easier for youth who were more confident in their ability to adapt to the various changes they experienced, and motivation was markedly increased.

"Certainly having her aunt who stood by her and continues to stand by her, who is not giving up on her; a huge source of resiliency for her."

- Staff interview

In a case where a youth was placed in care following multiple instances of acting out (not attending school, using drugs and alcohol, getting into fights), the manager noted the importance of developing a trusting relationship between this youth and her primary care-taker, her grandmother, in order to allow for new and positive experiences to emerge between them:

"I think the transition worked, because she wanted to be different. I think it worked because she was able to behave in ways that build up trust with her grandmother.

So her grand-mother had a little confidence in her and she had more confidence in her grandmother because she was beginning to talk to her, and be more supportive."

- Manager interview

Staff members observed that contact between parents and youth was often difficult for youth. Due to the fact that this residential placement was a last resort, most youth came from families with long histories of psychosocial problems. Therefore, despite their desire to spend time with family members in the residence, staff felt that parental contact was, at times, associated with distress.

Client talked to me about how her [family] was always letting her down and how she feels like she is going to explode when she talks to [family]. She vented how she feels left out when her [family] talks about other family members.... Client has requested that we do not share info on her with her mom and that she doesn't want to talk to her anymore.

- Individual log

Managers and staff felt that continuity in care provided by the residence and connections between youth and residential staff were important motivators for youth who connected with their primary worker.

"I think it [that what helped the youth's transition] would be the relationship she had with her worker. I think the primary worker really pushed her to look at some of the behaviours. The primary worker really, really pushed her; really did a lot of individual one-on-one work counselling sessions with her."

- Manager interview

Managers report that following youths' transition out of care, all the youth have maintained contact with educators from the residence. Some youth called to give news while others made contact when needing to talk or ask advice.

Managers and staff felt that youth established continuity and connection not only with specific resource people in their environment but also with their culture. Managers and staff considered it positive when youth took part in traditional activities in residence, such as sewing, carving, and traditional games, or when they developed skills and practiced elements of their culture on a daily 


\section{First Peoples Child \& Family Review, Volume 7, Number 1, 2012}

basis within their communities. It was also felt that practicing traditional activities at the residence allowed youth to symbolically maintain connections with family members and cultural identity.

"She participated here in throat-singing, she's got skills. And what she's got going for her as well is that both mother and grandmother are throat-singers. They are well known for their singing I mean, so that's something that she can connect up with, with her family."

- Manager interview

"She's still finding activities to do like traditional sewing because that's one of the things we stressed that she did here that would be important if they hook her up in the community."

- Manager interview

\section{Obstacles to reintegration}

Among the 11 youth who had left care prior to the interviews with staff, all returned to close or extended family in their home communities. From post-care contacts with youth managers, it was reported that three of these individuals were incarcerated in the months following transition and two returned to the residence in the six months following their transition home. Some apparently had felt intense emotional difficulties soon after returning to their communities, while others returned to old habits, such as drinking or not attending school, but with moderation and fewer repercussions on their daily lives.

"The fact that if she's doing it [drinking], she's not doing it to a certain extent that it is disrupting her and putting her in contact with the law and those kinds of things. So that's good."

- Manager interview

Interviewee: "We certainly had instances where we got a call that she's gone to the hospital, that she tried to kill herself or we got a call that there was a concern she might freeze to death because she had drank so much she would be laying outside, and somebody came by and discovered her and helped her. Yep."

Interviewer: "So she still has some difficulties...."

Interviewee: "Has some difficulties. Will always have some difficulties and it's continuously trying to be alive and get something out of life."

- Manager interview

"Well, I know that.... She actually called us last week to say she just got in jail for drinking and fighting.... So that's not uncommon. That's not uncommon for our girls and boys, when they go back [to their community] to drink and to fight. Not uncommon."

- Manager interview

According to staff, youth had difficulty adopting new life-styles in old contexts. Managers and staff identified many factors as potential obstacles to what they perceived as being a healthy reintegration: returning to difficult home environments; lack of continuity in services and relationships; anxiety and ambivalence related to transition. Finally, for some youth particularly those with criminal status or complications in the decision-making process - an important obstacle for their transition and reintegration was the lack of time for preparation. 


\section{Inuit youth transitioning out of residential care}

According to staff, the greatest obstacle to reintegration was having to return to contexts that often had not changed, and thus presented the same unhealthy environments from which the youth was taken in the first place. During their reintegration back to their communities, youth had to deal with alcohol and substance abuse among friends and peers, violence and neglect, lack of social and health resources, and lack of opportunities and/or activities, causing intense feelings of boredom.

"But all the girls will tell you that there's nothing to do, except to hang out at the co-op with friends, to smoke, to drink, to do drugs. There's nothing else to do."

- Staff interview

"He went back to [community name] and he was living with [family member]. He then didn't want to go to his house because his [family member] was drinking, and he didn't want staff to see that.... So, it was a setup. You're talking about a kid with really heavy substance abuse issues and then with no preparation, just walk right back to that thing. ..."

- Manager interview

Staff described how these community contexts revived unhealthy dynamics and coping mechanisms, such as drinking, using drugs, and taking part in delinquent activities. With limited personal and community resources, some youth adopted available strategies to "numb the pain."

Interviewer: "Why would they go back to drinking?

Participant: "To drugs and alcohol and whatever? Because it's there. Most of the time it's friends that have stuff for you, it's already there and that is where they get away from their problems."

- Staff interview

According to staff, different forms of discontinuity in care and relationships were major obstacles to reintegration. They described first the lack of specialized care required for drug and alcohol addictions and psycho-emotional difficulties. The loss of specific resource people was also noted as a major obstacle to "successful" transitions. This included the frequent turnover of community-based workers.

"The [social] worker he had, just left and had given it [the case] to another [social] worker. By the time I made sure of his transition plan, she said she was no longer the worker. So then it was another worker; and then, by that time, it was November. And he was coming home in November."

- Manager interview

In our observations on residential grounds, and talking to youth, we noted they often developed a strong attachment not only to the staff and other youth but also to the residence. Youth in care gave each other special titles such as soul-mate, sister, or brother. It was not rare that youth spoke of the residence as being their "fake home." Girls spontaneously cleaned open spaces to make them feel more "cozy." Despite common frustrations related to placement, and the repeatedly expressed desire to return to the community, youth reported feeling safe within the residence. Transitioning back to their communities often meant losing these relationships and the feeling of comfort; these losses were experienced against the backdrop of other personal loses endured throughout their lives. 


\section{First Peoples Child \& Family Review, Volume 7, Number 1, 2012}

Discontinuity in care was a particular problem for youth who age out of care when they reached the age of majority and were no longer eligible for services, as well as for youth who were classified as young offenders. In such cases, youth benefited from few, if any, services within their communities.

"And when the kids are not [under] youth protection, the worker's involvement in the community is very minimal. They just want to make sure that they have done what they needed to do. So there's no chance of going home for a visit before the measures run out because it's young offenders. So it's not like when its two weeks before going back or a month, we can plan to start sending him up. We just can't do that."

- Manager interview

In this excerpt, the manager discusses the complexities surrounding the planning of care for youth under the Youth Criminal Justice Act. In such cases, youth must strictly abide by their court sentence, which generally involves placement for a specified period of time. During this time, trial visits to help youth create networks in the community and re-experience life at home are not possible. As well, child welfare services have mandates with clients until they reach a specific age. In this particular region, the mandate ends at the age of majority, after which funds are not available for follow-up and care provided within communities is minimal. Youth were very aware of this system and some expressed indifference with regard to available services, looking forward to acquiring status as independent "adults," while others felt anxiety when faced with a lack of services. Managers felt that this legal status was an important impediment to change among youth, and dramatically reduced the time and resources available to prepare for reintegration.

Interviewer: "And maybe because they're older that it didn't work. . . ."

Participant: "Exactly. Not nearly enough time to try to impact the kind of severe delinquency that they were involved in."

Interviewer: "Do you think that if they stayed longer here, it would've changed?

Participant: Change is a big word. I think I'm certain it would have certainly had an impact on their behaviours. . . . And also, they don't engage because there's this mystical magical date of when I turn 18 and free and I'm an adult and you can't tell me anything."

- Manager interview

Change in structure and discipline from residential settings to home was perceived as being a major form of discontinuity. Gains made in care were viewed as resulting from structure and discipline, continual reinforcement, and consistency in the consequences given to youth, and it was felt that such structure and consistency was often lacking within the homes of these youth.

Interviewer: "Is it good for them to have a tight schedule with lots of activities?

Interviewee: It is but at the same time when they leave here they are going to be in culture shock. Because it's so different from what they live up there, so it's as if it helps them to feel better but it doesn't prepare them for reality.

It [transition] is really hard for them because I think that deep down inside they do want to change, they want to keep this strict lifestyle and just someone to care about them. . . . So it's hard for them to adapt to [pause] freedom."

- Staff interview 


\section{Inuit youth transitioning out of residential care}

Staff and managers also discussed their perception of youth's anxiety when facing transition. According to interviewees, youth were conscious of the obstacles they would face when returning home.

"Oh, lots of, lots of anxiety. Lots of, lots of sadness. Lots of concerns about: am I going to, am I going to be able to do this? You know, so. ... She had no confidence about doing it. So, the anxiety was not as nearly high as it had been the other times. And at other times shed actually changed her mind and didn’t go."

- Manager interview

[Name of youth] is telling us: "I'm scared, and I'm scared because I know when I go, I'm gonna be bored, because the school there is boring, it's nothing like here. There's nothing to do. And so all my friends, they drink, they smoke, they use drugs, so it's going to be very difficult for me. How am I going to be able to say no and not do it?"

- Manager interview

Peer pressure, bullying, and ostracism were seen as major impediments to reintegration. Our time spent with youth allowed us to hear them describe how boredom and bullying within the communities is a major stressor in their daily lives.

"He was 17 and they didn't want him back in the community. So they figured, we'll kinda keep him there until he's $18 . "$

- Manager interview

"She burned so many bridges, I mean, both in the trust of so many people, because of the violence, because of the stealing, because of the drugs. I mean, people were just very reluctant to have her back in the community."

- Manager interview

Being placed away from the community also opened the door to various post-discharge options with regard to living arrangements. Youth got to see the city and be in contact with family members or friends living in the city. These experiences broadened the imagination of youth who aged out of care, but sometimes created anxiety and confusion.

"He didn't know where he was going. He would ask me: where am I going? What's going on? Who is going to take me? So I suggested that we meet, him, myself and his social worker, all together. We went over the options, we looked at what was viable, what made sense and all the anxiety went down, all of the sudden he was not angry and didn't have an attitude."

- Staff interview

A final obstacle to a positive transition, as perceived by managers and staff, was the lack of time available for preparation. Decisions on transition sometimes depended on judicial decisions or other factors that derailed systematic planning and preparation. On some occasions, youth found out about having to transition back home only weeks or even days prior to the actual event. Following a scheduled court appearance, youth were told whether their stay in the residence would continue or a return home was granted. Youth might then only have time to return to the residence to pack their bags. On the other hand, they might have a prolonged period of anticipation over the possibility of going home and, when told they must stay longer, returned to the residence frustrated and disappointed. 
First Peoples Child \& Family Review, Volume 7, Number 1, 2012

"I don't know if it was a last minute thing, but we were definitely preparing him for an extra stay. We were looking at circus schools. He was very athletic. He liked to do like acrobats. So we were trying to look for a gymnastics or circus school for him to attend. So we were trying to get the positive of staying with us, so that he wouldn't get down. And then the day before the court, she (the social worker) said: no, we changed the recommendation, he's coming back."

- Manager interview

" Unfortunately advance notice [of when youth will be transitioning out of care] is not a common thing. ... when they do have the time, when they are given a month, two months, three months advance notice, everyone is able to run around and build support for them and try to get them back to school, get them ready for a job, get them to meet the people to support them in their community, you know, I can have a proper termination where we work on focusing on the future and their strengths and get them kind of ready for that emotional departure from everyone."

- Staff interview

\section{Structural elements and program development}

The residential program and policies developed and evolved throughout the period of the internal quality assessment. Here we describe the structural elements inherent to the youth care services of this region as well as the program elements developed to ease the transition of youth as a function of the manager's and the staff's perception of the youth's needs and experiences.

The official procedure for decision-making was hierarchically structured and dependent on the Act under which the youth was placed (see Table 1, p. 66). The intricate relationships and dynamics between the various individuals involved in the youth's life create important differences in who may influence the decision process. Managers provided examples of who is involved and how the decision process might fluctuate from case to case and could include family members, social workers, judges, educators, managers, therapists, and the youth themselves. When discussing the transition of a particular youth who was at the residence under voluntary measures, the manager explained that they encouraged the youth to stay due to the perception that his family context was not ideal at the moment of transitioning.

"I think we did it in collaboration with DYP [Department of Youth Protection] they based it a lot on our feedback.... We actually encouraged him to stay on. ... But he decided he would rather go back than stay here longer."

- Manager interview

In a second case, the manager explained how the social worker within the community established a plan in communication with family members, lawyers, and the residence, but could repeatedly modify the plan as a function of the family circumstances, perceptions of the youth's behaviour, or other unknown reasons. These changes make it difficult to develop a transition plan.

"His planning was done in conjunction with the [social] worker. Now it's a little more difficult because the decisions were getting changed very often. So at one point the social worker was asking for three extra months and then she wasn't and then she was asking for it again. Like we were preparing him for an extra stay, and the day before she told me he was going home."

- Manager interview

(c) Sarah L. Fraser, Mélanie Vachon, Maria J. Arauz, Cécile Rousseau, and Laurence J. Kirmayer 


\section{Inuit youth transitioning out of residential care}

Table 1: Types of placements

\begin{tabular}{|l|l|l|l|}
\hline & \multicolumn{1}{|c|}{ Social Services Act } & \multicolumn{1}{|c|}{ Youth Protection Act } & \multicolumn{1}{|c|}{ Criminal Justice Act } \\
\hline $\begin{array}{l}\text { Reasons for } \\
\text { placement }\end{array}$ & Voluntary placement & $\begin{array}{l}\text { Security and } \\
\text { development are } \\
\text { compromised }\end{array}$ & Criminal activities \\
\hline $\begin{array}{l}\text { Responsibility for } \\
\text { decision making }\end{array}$ & Youth protection & $\begin{array}{l}\text { Youth protection } \\
\text { court }\end{array}$ & YCJA court \\
\hline $\begin{array}{l}\text { Interactions in } \\
\text { decision }\end{array}$ & $\begin{array}{l}\text { Social work } \\
\text { will interact } \\
\text { with residential } \\
\text { workers and other } \\
\text { professionals }\end{array}$ & $\begin{array}{l}\text { DYP social } \\
\text { workers make } \\
\text { recommendations, } \\
\text { other professionals } \\
\text { and workers may offer } \\
\text { recommendations to } \\
\text { the social worker }\end{array}$ & $\begin{array}{l}\text { professionals working } \\
\text { with the youth may } \\
\text { provide the court with } \\
\text { recommendations }\end{array}$ \\
\hline
\end{tabular}

Once the social worker from youth protection services decided that a youth would transition out of care, the residential managers adopted a number of practices and activities to aid youth in their reintegration. Managers were concerned with ensuring that youth leave care with a safety plan that included identifying specific resource people whom the youth trusted. Planning also included developing an education and work plan when appropriate. The interventions for preparing youth to return to their communities were tailored to youth's specific needs as determined by the managers and social worker.

This planning required communication between the residence social worker and resources within communities (employers, teachers, family, and other potential resources). Educators accompanied youth on trial visits to their community to help youth reintegrate at their own pace and to aid them in developing trusting relationships with the identified resources. As a manager noted,

"[There are] lots of telephone planning conversations; going [to the community] to the family; the primary worker, going up and meeting with youth and the worker; finding a resource in the community"

"I think she must've gone like three or four times. Three, four days at this time; a week at this time, as an integration back into the family home and into the community."

In order to create a sense of continuity in relationships and connection with the residence, managers and staff members organized "goodbye" rituals for youth who were about to leave. Youth were offered a departure gift. On the boys' section of the residence, they all chose a piece of jewellery, which became a sign of belonging and connection to the group.

"The boys have all chosen jewellery and a bracelet. That comes from one of our staff who wears a big thick choker and thick bracelets in stainless steel, and I think the guys kind'a look at that as cool, so that became, once one picked that as a gift, everybody else did it too."

- Manager interview 
First Peoples Child \& Family Review, Volume 7, Number 1, 2012

A supper was organized for the departing youth, either with the whole group or just with their primary worker, according to the youth's request. Youth who left the residence often returned to their communities with residential staff. Staff members remained in the community for a few days as the youth began to reintegrate. During this period staff would meet with the family, help youth connect with community services, and offer support when needed. Following their transition home, youth could communicate with staff members at the residence at any time. For two youth who did not call the residence in the weeks following their transition, staff made contact with them for follow-up.

Apart from the program elements specific to the transition period, managers developed a program and policies that they felt would help youth both in care and after care as a function of the perceptions of facilitators and obstacles noted above.

This residential program was developed on the model of the Circle of Courage (Brendtro, Brokenleg, \& Van Bockern, 1990). This empowerment approach was based on Native philosophies of child care and attempts to foster courage by developing four abilities and values among youth: belonging, generosity, mastery, and independence (Brendtro, Brokenleg, \& Van Bockern, 1990). Educators received a three-day training session on how to implement these values on a daily basis. The concepts were used concretely in specific activities. For example, during girl team meetings, staff would give specific girls a star on the wall of stars if educators felt that youth had displayed one of the four values fostered in the circle of courage. Aside from these concrete examples of the incorporation of these values in activities, it was unclear how the values were understood by the educators and integrated in their interactions with youth and within the general program.

Specific traditional activities were also included in the program, such as sewing, carving, storytelling, throat signing, Inuit games, as well as traditional meals. There was a hope that these activities would help youth gain insight into their behaviours and reconnect with their culture and family.

"Hopefully, the work that [cultural broker/educator] and people have been doing for 'girl talk' and the 'circle of courage', - that's what they're doing - [learning to be] able to say no and being able to walk away [from trouble]. Hopefully it's gonna work. The reality is that Wednesday you might fail and not be able to say no and walk away. But hey, if you can do it Monday, Tuesday, Thursday, Friday, good for you."

- Manager interview

Youth could communicate with family members on a daily basis, and staff contacted families and social workers regularly to maintain communication. Youth had daily computer time scheduled to enhance contact between friends and family. A third unit was opened to allow family members to visit their children while in residence. During these visits, which would normally last two to four days, youth could stay with their family in this separate unit. Also, if managers and staff members felt that the transition period may be particularly difficult for the youth and that there was a possibility that it would not succeed on a first trial, rooms were left vacant for a few weeks to provide youth the opportunity to return to residence.

"See, even when he left, it wasn't 'this is final,' we had made like a first plan where he went up for two weeks and we saw how that went and if it went well, then before [month] he would go up. But we still had ... we left his bed open until [month], just in case.... And he knew that. Like, you know: 'This is a test. You're going up. You did well last time so if you can sort of keep your end of the bargain, then you'll stay in the community, and if not, you have to come back and spend some more time with us." 


\title{
Inuit youth transitioning out of residential care
}

\section{- Manager interview}

In cases where youth requested or required, as determined by the community social worker, to return to the residence once these few "transition" weeks were over, they were placed on a waiting list and returned for a second stay.

Managers and staff's interactions with youth influenced not only the program development on a more permanent basis but also the attention and resources mobilized on a more personal basis. Spending such a long period with the youth and witnessing their distress can be emotionally difficult for staff members, especially during times of transition. In this example, the manager discussed his feelings about the transition of one of the youth who has had repeated suicidal attempts in the past:

$$
\begin{aligned}
& \text { Interviewer: "And how did you personally experience [her] departure?" } \\
& \text { Interviewee: (Silence) "Anxiety, fear.... Because I'm still not sure how long she'll live." } \\
& \text { - Manager interview }
\end{aligned}
$$

When staff and managers felt that youth were anxious about returning home, this anxiety sometimes mobilized special attention and care from staff members, who showed a strong desire and motivation to offer care pre- and post transition.

\begin{abstract}
"She had asked me: 'When I leave from here there is a possibility for me to continue seeing you?' and I said 'Yeah, we can work something out', and we spoke about that, and developed a plan if she is [in the city] that she could come see me. And if she is [in the community] maybe we can talk on the phone. Maybe we can speak to her social worker."
\end{abstract}

- Staff interview

\section{Discussion}

The objective of this exploratory study was to examine the obstacles and facilitators for Inuit youth when transitioning from residential care back to their home communities, as perceived and understood by the managers and staff members involved in program development and service provision. Five of the six individuals interviewed in this study were non-Aboriginal. Moreover, all individual logs were written by non-Aboriginal staff members. The researchers and research assistants were also non-Aboriginal. The results therefore primarily reflect the experiences of non-Aboriginal social service workers. It is important to note, however, that the results were shared and discussed with an Inuit educator/cultural broker and an Inuit Elder who gave feedback that was integrated into the final interpretation.

Although the perspectives of the youth, their families, and communities were not assessed, the views of professional staff involved in service development and provision are important for understanding the values and orientation toward culture and social services that guide program development in residential care and shape what is viewed as being "culturally competent" care when planning the transition of youth back to their communities.

In assessing whether youth were ready to transition back to their communities, the major questions managers had were: 1) Have their problematic behaviours changed? 2) Are the youth likely to maintain these behaviours in the community? And 3) How can we plan the transition? Elements of a positive transitions included going to school, keeping a job, having structure within 
First Peoples Child \& Family Review, Volume 7, Number 1, 2012

the family environment, less suicidal ideation and attempts, as well as a reduction of alcohol and drug use. These criteria are consistent with the professional and institutional mandate of "stabilizing" youth presenting high-risk behaviours.

\section{Obstacles to transition}

The obstacles discussed by interviewees were mostly forms of discontinuity within the structural system, including disruption in care after the age of majority, and certain last-minute legal decisions concerning the moment at which the transition back to communities will take place.

In this study, of the five youth who attained the age of majority at the time they left care, three were incarcerated in the months following. Longitudinal and retrospective studies assessing outcome of youth leaving care at the age of majority suggest high rates of incarceration, homelessness, and psychiatric illness (Cauce \& Morgan, 1994; Fall \& Berg, 1996; Fitzgerald, 1995; Lindsey, Kurtz, Jarvis, Williams, \& Nackerud, 2000; Maclean, Embry, \& Cauce, 1999). Having services abruptly withdrawn has an impact on youths' ability to adjust to independent living (Mann-Feder \& White, 2003; Thompson, 1996).

A second major category of obstacles was described as unstructured or challenging post-care environments, including exposure to alcohol and substance abuse in families and/or communities, boredom, and lack of opportunities. The literature suggests that the stability and quality of placement following discharge greatly influence a youth's ability to maintain any gains made during their residential stay (Lewis, 1982; Wells, Wyatt, \& Hobfoll, 1991). Boredom and bullying within communities may be important social determinants of health, and have been identified as targets for mental health prevention and intervention programs for Aboriginal youth (Fortune, Sinclair \& Hawton, 2008; Kirmayer, 1994; Kirmayer et al. 2009; Mohajer, Bessarab, \& Earnest, 2009; Stevenson \& Ellsworth, 2003).

\section{Facilitators of transition}

Most of the strategies put into place by managers and staff to facilitate transition remained within the existing structure of care. Strategies to facilitate transition by strengthening continuity of care included encouraging youth to stay longer in care, accompanying youth to their community to help them create new social, educational, and job networks, creating rituals before departure, offering symbolic gifts, and offering post-care support via telephone. Continuity with family was supported by looking for extended family members who could foster the youth post-care, and creating opportunities for communication between youth and the community. To provide cultural continuity, managers and staff strived to incorporate "traditional activities" into the program.

Concerning continuity with family, some authors have suggested that greater contact during placement increases the likelihood of returning home following placement (Cantos, Gries \& Slis, 1997) and maintaining behavioural and psychological gains made during placement (Hair, 2005; Stage, 1999). There is very little literature assessing the involvement of parents of Aboriginal youth in care. However, work by Delfabbro, Barber, and Cooper (2002) found that in their sample of Australian youth in care, Aboriginal parents tended to have less contact with their children, geographical distance being a major impediment to parental contact during placement. Many Canadian First Nation communities and most Inuit communities are remote and isolated. Any 


\section{Inuit youth transitioning out of residential care}

services provided in urban areas may therefore be difficult to access, due to both financial and logistical constraints, and could potentially decrease the likelihood that youth will maintain any positive behavioural changes.

\section{Program development and culturally competent care}

Betancourt and colleagues (2003) defined cultural competence as the ability to provide care that meets the social, cultural, and linguistic needs of individuals and groups. Our data raise three basic questions about the application of this notion of cultural competence in residential settings for Aboriginal youth.

First, who assesses the needs to be met by culturally competent care? Data gathered from interviews and observations suggest that the criteria to determine when youth could transition back to communities and whether the transition was positive or not depended largely on professionals' understandings of the needs of youth. Whether these criteria and understanding of needs were congruent with those perceived by youth, families, and communities was not assessed. This is an important limitation for the study, but it mirrors the gap within the system of care. During our 14-month assessment, we witnessed no explicit and systematic attempt to obtain the perceptions of families and communities regarding youths' wellbeing. There may be various reasons for this gap, including geographical distance, a lack of formal ties between the institutions and the communities, and the tendency of managers and staff to focus on daily crisis situations.

Second, what counts as "culture"? Managers and staff felt that youth's ability to sustain a connection with their "culture" via a variety of traditional activities enhanced their ability to reduce harmful behaviours and to engage in educational, social, and economic activities following their transition. The incorporation of culture via traditional activities, the presence of Aboriginal staff in care, and the ability to speak one's mother tongue have been discussed as important steps toward developing cultural competence in rehabilitative or healing programs (Gone, in press). Gone reports: "Even in therapeutic settings where indigenous healing practices are formally absent, token gestures to indigenous cultural practices are thought to at least reassure First Nations clients that available offerings of 'mainstream' therapeutic approaches can indeed be made relevant and useful for them, too." However, considering that the "cultural" activities were not always run by Aboriginal people, that they did not take place with family members, as they normally would, and that they sometimes had to be substantially adapted to the urban reality (e.g., a gun handling class), we wonder at what point culture loses its communal or collective meaning.

Finally, whose agenda does cultural competence serve? Residential workers have the mandate of stabilizing youth in crisis. These youth often come from families and communities with long histories of trauma. Managers and staff feel that no matter how hard they worked with the youth in the residence, they would ultimately return to harsh environments with few available services. Considering that the current system of care has been unable to address the structural causes of the over-representation of Aboriginal people in care and considering the long-lasting intergenerational effects of residential school experiences on Aboriginal people and communities, some may argue that no matter what is put in place, transitioning from residence to community cannot be culturally appropriate because it implies that youth were taken away in the first place. 
When working with Aboriginal peoples, cultural competence requires meeting the needs and expectations of youth, families, and communities at large (Libesman, 2004). Structural and institutional power differences must be addressed (Libesman, 2004; Williams, 1997). In order to target some of the underlying causes for the high rates of placements of First Nations, Métis, and Inuit youth of Canada - poverty, lack of child care services, alcohol and substance abuse, ruptures in transmission of parenting skills (Blackstock \& Trocmé, 2005; Lafrance \& Bastien, 2007; Rae, 2011) - some have suggested the creation of community-based, family-oriented programs that attempt to meet the needs not only of the youth, but their families and communities (Bennett, Blackstock, \& De La Ronde, 2005; CASW, 1994, p. 158; Blackstock \& Trocmé, 2005; Lafrance \& Bastien, 2007; Libesman, 2004; National Indian Child Welfare Association, 2000; Rae, 2011). Working at the community level enhances cultural competence by creating links with community services, as well as fostering and strengthening leadership within the community (Libesman, 2004; Pierce \& Pierce 1996). Finding community-based solutions would also help break the transgenerational cycle of the removal of children into placement.

These questions remind us of the complexity of creating "culturally competent" care within large systems and institutions of care. They point toward the need to develop other models that give more emphasis to issues of power, to insure that the voices and perspectives of Aboriginal youth, families, and communities are fully engaged and can direct the organization and delivery of culturally safe and appropriate health and social services (Brascoupé \& Waters, 2009; Kirmayer, 2012).

\section{Limitations and Future directions}

This study was based on data collected for quality assurance purposes and therefore the data available for analysis is limited. This work is based on interviews with six staff concerning the experiences of 11 youth. However, the use of participant observation over a period of 14 months provided rich background information to understand the context of care and the experiences of the youth in care, and this informed the interpretation of the interview data. Interviews were only conducted with staff members in the residence. Moreover, the researchers and research assistants involved in the observation and analysis are non-Aboriginal.

Multiple actors are involved in the transition, including social workers, judges, lawyers, family members, community members, and the youth themselves. Different stakeholders may have distinct views with regard to wellbeing, the efficacy of residential programs, and what are considered to be positive outcomes of transition out of care.

A better understanding of the obstacles and facilitators to transition would require the perception and experiences of the youth transitioning out of care, the families as well as the communities. As noted previously, a culturally safe and competent program must aim to meet the social, cultural, and linguistic needs of youth, families, and communities. Criteria to determine whether transition is successful or not must be developed in collaboration with these different actors to determine what their needs are, and how these needs can be met. Further work is essential to listen to the voices of youth, families, and communities, engage them as active agents in the design and delivery of care, and insure that services respond to their needs. 


\section{Inuit youth transitioning out of residential care}

\section{References}

Anglin, J.P. (2004). Creating "Well-Functioning" Residential Care and Defining Its Place in a System of Care. Child \& Youth Care Forum, 33 (3), 175-192.

Bascoupé, S. \& Waters, C. (2009). Cultural safety: Exploring the applicability of the concept of cultural safety to Aboriginal health and community wellness. Aboriginal Health Journal, 5 (12), 6-41.

Bates, B.C., English, D.J., \& Kouidon-Giles, S. (1997). Residential treatment and its alternatives: A review of the literature. Child \& Youth Care Forum, 26 (1), 7 - 51.

Betancourt, J. R., Green, A. R., Carrillo, J. E., \& Ananeh-Firempong, O. (2003). Defining cultural competence: A practical framework for addressing racial/ethnic disparities in health and health care. Public Health Reports, 118 (4), 293-302.

Blackstock, C. \& Trocmé, N. (2005). Community-based child welfare for aboriginal children: supporting resilience through structural change. Social Policy Journal of New Zealand, 24, 12-33.

Blackstock, C., Trocmé, N., \& Bennett. (2004). Child maltreatment investigations among Aboriginal and nonAboriginal families in Canada. Violence Against Women, 10 (8), 1-16.

Blackman, M., Eustace, J., \& Chaudhury, T. (1991). Adolescent residential treatment: A one to three year followup. Canadian Journal of Psychiatry, 36, 472-479.

Blumer, H. (1969). Symbolic Interactionism: Perspective and Method. Englewood Cliffs, NJ: Prentice-Hall.

Braun, V., \& Clarke, V. (2006). Using thematic analysis in psychology. Qualitative Research in Psychology, 3, 77-101.

Brendtro, L., Brokenleg, M., \& Van Bockern, S. (1990). Reclaiming youth at risk: Our hope for the future. Bloomington, IN: National Educational Services.

Bruner, J. (1993). Do we "acquire" culture or vice versa? Behavioral and Brain Sciences, 16, 515-516.

Burns, B. J., Hoagwood, K., \& Mrazek, P. J. (1999). Effective treatment for mental disorders in children and adolescents. Clinical Child and Family Review, 2, 199-254.

Camilleri, C. (1989). La culture et l'identité culturelle : Champ notionnel et devenir. In C. Camilleri, C. \& M. CohenEmerique. Chocs de cultures : concepts et enjeux pratiques de l'interculturel ( $p$ p 21-77). France : L'Harmattan

Canadian Association of Social Workers (CASW). (1994). The Social Work Profession and the Aboriginal People : CASW Presentation to the Royal Commission on Aboriginal Peoples, The Social Worker, 62 (4),158.

Cauce, A., \& Morgan C. J. (1994). Effectiveness of intensive case management for homeless adolescents: Results of a three month follow-up. Journal of Emotional and Behavioural Disorders, 2, 219-227.

Cleaver, H. (1998). Contact: The social worker's experience. Adoption and Fostering, 21, 34-40.

Cross, T., Bazron, B., Dennis, K., \& Isaacs, M. (1989). Towards a culturally competence system of care. Washington, DC: National Technical Assistance Centre for Children's Mental Health, Georgetown University Child Development Centre.

Cunneen, C., \& Libesman, T. (2000). Postcolonial trauma: The contemporary removal of indigenous children and young people from their families in Australia. Australian Journal of Social Issues, 35 (2), 99-115.

Delfabbro, P.H., Barber, J.G., \& Cooper, L. (2003). The role of parental contact in substitute care. Journal of Social Service Research, 28 (3), 19-40.

Demazière, D. (2011). L'entretien biographique et la saisie des interactions avec autrui. Recherches Qualitatives, 30 (1), 61-83. 


\section{First Peoples Child \& Family Review, Volume 7, Number 1, 2012}

Fall, K. A., \& Berg, R.C. (1996). Behavioural characteristics and treatment strategies with homeless adolescents. Individual Psychology, 52, 431-440.

Fanshel, D. (1975). Parental visiting of children in foster care: Key to discharge? Social Service Review, 49, 493-514.

Fitzgerald, M. D. (1995). Homeless youth and the child welfare system: Implications for policy and Service. Child Welfare, 74, 717-731.

Fortune, S., Sinclair, J., \& Hawton, K. (2008). Adolescents' views on preventing self-harm: a large community study. Social Psychiatry and Psychiatric Epidemiology, 43, 96-104.

Fraser, S., Rousseau, C., Burmester, P., Arauz, M-J. (submitted). Culturally appropriate care, a multicultural task: Assessing the needs of Inuit youth under youth protection.

Frensch, K.M., \& Cameron, G. (2002). Treatment of choice or a last resort ? A review of residential mental health placements for children and youth. Child \& Youth Care Forum, 31 (5), 307 - 339.

Galley, V. J. (2010). Summary of Aboriginal over-representation in the child welfare system. Saskatchewan Child Welfare Review Panel. Retrieved from http://saskchildwelfarereview.ca/Aboriginal-Over-representation-VGalley.pdf.

Gone, J.P. (in press). Redressing First Nations historical trauma: Theorizing mechanisms for Indigenous culture as mental health treatment. Transcultural Psychiatry.

Hair, H.J. (2005). Outcomes for children and adolescents after residential treatment : A review of research from 1993 to 2003. Journal of Child and Family Services, 14 (4), 551-575.

Hillan, L. (2005). Reclaiming residential care: A positive choice for children and young people in care. Acton, ACT: The Winston Churchill Memorial Trust of Australia.

Kirgin, K.A., Braukmann, C.J., Atwater, J.D. \& Wolf, M.M. (1982). An evaluation of teaching-family (Achievement place) group homes for juvenile offenders. Journal of Applied Behavioural Annals, 15 (1), 1-16.

Kirmayer, L.J., Hayton, B., Malus, M., Jimenez, V., Dufour, R., Quesney, C., ... \& Ferrara, N. (1994). Suicide in Canadian Aboriginal Populations: Emerging Trends in Research and Intervention: A Report for the Royal Commission on Aboriginal Peoples, Report Number 1. Montreal, QC: Culture \& Mental Health Research Unit, Institute of Community \& Family Psychiatry, Sir Mortimer B. Davis-Jewish General Hospital.

Kirmayer L.J., Fraser, S.L., Fauras V., \& Whitley, R. (2009). Culture and Mental Health Research Unit Report No. 14. Montreal. Retrieved from At www.namhr.ca/pdfs/Suicide-Prevention.pdf.

Kirmayer, L.J., (2012). Cultural competence and evidence-based practice in mental health: Epistemic communities and the politics of pluralism. Social Science \& Medicine, 75, 249-256.

Lafrance, J., \& Bastien, B. (2007). Here be Dragons! Breaking down the iron cage for Aboriginal children. In I. Brown, F. Chaze, D. Fuchs, J. Lafrance, S. McKay, \& S. Thomas Prokop (Eds.), Putting a human face on child welfare: Voices from the Prairies (pp. 89-113). Prairie Child Welfare Consortium Retrieved from http://www.cwrp.ca/fr/ node/1013.

Larzelere, R.E., Dinges, K., Schmidt, D., Spellman, D.F., Criste, T.R., \& Connell, P. (2001). Outcomes of Residential Treatment: A Study of the Adolescent Clients of Girls and Boys Town. Child \& Youth Care Forum, 30 (3), 175-185.

Lavergne, C., Dufour, S., Trocmé, N., \& Larrivée, M-C. (2008). Visible minority, Aboriginal, and Caucasian children investigated by Canadian Protective Services. Child Welfare, 87 (2), 59-76.

Lewis, W. W. (1982). Ecological factors in successful residential treatment. Behavioural Disorders, 7, 149-156.

Libesman, T. (2004). Child Welfare approaches for indigenous communities: International Perspectives. Child abuse prevention issues, National Child Protection Clearinghouse, 20 Retrieved from http://www.aifs.gov.au/nch/pubs/ issues/issues20/issues $20 . h t m l$

(C) Sarah L. Fraser, Mélanie Vachon, Maria J. Arauz, Cécile Rousseau, and Laurence J. Kirmayer 


\section{Inuit youth transitioning out of residential care}

Lieberman, R. E. (2004). Future directions in residential treatment. Child \& Adolescent Psychiatric Clinics of North America, 13, 279-294.

Lindsey, E. W., Kurtz P. D., Jarvis, S., Williams, N. R., \& Nackerud, L. (2000). How runaway and homeless youth navigate troubled waters: Personal strengths and resources. Child and Adolescent Social Work Journal, 17, 115-140.

Lyons, J.S., Woltman, H., Martinovich, Z., \& Hancock, B. (2009). An outcomes perspective of the role of residential treatment in the system of care. Residential Treatment for Children \& Youth, 26 (2), 71-91.

Maclean, M. G., Embry, L. E., \& Cauce, A. M. (1999). Homeless adolescents paths to separation from family: Comparison of family characteristics, psychological adjustment, and victimization. Journal of Community Psychology, 27, 179-187.

Malterud, K. (2001). Qualitatative research: standards, challenges, and guidelines. The Lancet, 358, 483-488.

Mann-Feder, V.R. \& White, T. (2003). Facilitating the transition from placement to independent living: Reflections from a program of research. International journal of Child \& Family Welfare, 6 (4), 196-204.

Mohajer, M., Bessarab, D., \& Earnest, J. (2009). There should be more help out here! A qualitative study of the needs of Aboriginal adolescents in rural Australia. Rural Remote Health, 9 (2), 1137.

National Indian Child Welfare Association, Cross, T.L., Earle, K., Echo-Hawk Solie, H., \& Manness, K. (2000). Systems of care promising practices in children`s mental health. Volume I. Cultural strengths and challenges in implementing a system of care model in American Indian communities. Comprehensive Community Mental Health Services for Children and Their Families program.

NVIVO qualitative data analysis software (2010). QSR International Pty Ltd. Version 9.

Office of the Auditor General (2011). Programs for First Nations on Reserves. June Status Report of the Auditor General of Canada. Ottawa. Retrieved from http://www.oag-bvg.gc.ca/internet/English/parl_oag_201106_04_e_35372.html

Pithouse, A., \& Parry, O. (1997). Fostering in Wales. Adoption and Fostering, 21, 41-49.

Prus, R.C. (1996). Interaction and ethnographic research: Intersubjectivity and the study of human lived experience. Albany: State University of New York Press.

Rae, L. (2011). Inuit Child Welfare and Family Support: Policies,Programs and Strategies. Ottawa: National Aboriginal Health Organization.

Rocher, G. (1968-69). Culture, civilisation et idéologie. In Introduction à la sociologie générale, Première partie : Laction sociale, chapitre 4, pp. 101-127. Montréal : Éditions H.M.H.

Rousseau, C., Rufagari, M-C., Bagillishya, D., \& Measham, T. (2004). Remaking family life: strategies for re-establishing continuity among Congolese refugees during the family reunification process. Social Science \& Medicine, 59 (5), 1095-1108.

Silva-Wayne, S. (1995). Contributions to resilience in children and youth: What successful child welfare graduates say. In J. Hudson \& B. Galaway (Eds.), Child welfare in Canada: Research and policy implications (pp. 308-323). Toronto: Thompson Educational Publishing.

Slot, N. W., Jagers, H. D., \& Dangel, R. F. (1992). Cross-cultural replication and evaluation of the teaching family model of community-based residential treatment. Behavioral Residential Treatment, 8, 341-354.

Stage, S. A. (1999). Predicting adolescents' discharge status following residential treatment. Residential Treatment for Children \& Youth, 16 (3), 37-56.

Stake, E. (2005). Multiple case study analysis. New-York: Guilford Press.

Stevenson, L. \& Ellsworth, Q. (2003). A national Inuit youth suicide prevention framework. Nunavut: Qikiqtani Inuit Association. 


\section{First Peoples Child \& Family Review, Volume 7, Number 1, 2012}

Thompson, G. (1996). Graduating from child welfare: A potentially life threatening transition. Canada's Children, 3 (1), 13-14.

Trocmé, N., Knoke, D., \& Blackstock, C. (2004). Pathways to the overrepresentation of Aboriginal children in Canada's child welfare system. Social Service Review, 78 (4), 577-599.

Tweddle, A. (2007). Youth leaving care: How do they fare? New Directions for Youth Development, 113, 15-31.

Vachon, M. (2010). Le groupe de discussion comme espace de soutien: briser l'isolement chez des survivantes du génocide rwandais. Recherches Qualitatives, 29(3), 133-144.

Wells, K., Wyatt, E., \& Hobfoll, S. (1991). Factors associated with adaptation of youths discharged from residential treatment. Children and Youth Services Review, 13, 199-216. 